Federal Reserve Bank of Minneapolis

Research Department Staff Report 215

Revised July 1997

\title{
A Model of Commodity Money, With Applications to Gresham's Law and the Debasement Puzzle
}

François R. Velde*

Federal Reserve Bank of Chicago

Warren E. Weber*

Federal Reserve Bank of Minneapolis

and University of Minnesota

Randall Wright*

University of Pennsylvania

\begin{abstract}
We develop a model of commodity money and use it to analyze the following two questions motivated by issues in monetary history: What are the conditions under which Gresham's Law holds? And, what are the mechanics of a debasement (lowering the metallic content of coins)? The model contains light and heavy coins, imperfect information, and prices determined via bilateral bargaining. There are equilibria with neither, both, or only one type of coin in circulation. When both circulate, coins may trade by weight or by tale. We discuss the extent to which Gresham's Law holds in the various cases. Following a debasement, the quantity of reminting depends on the incentives offered by the sovereign. Equilibria exist with positive seigniorage and a mixture of old and new coins in circulation.
\end{abstract}

* The views expressed here are those of the authors and not necessarily those of the Federal Reserve Banks of Minneapolis or Chicago or the Federal Reserve System. We thank Arthur Fishman, Angela Redish, Thomas Sargent, Theodosios Temzelides, and seminar participants at the Federal Reserve Banks of Minneapolis and Philadelphia, the Penn Macro Lunch Group, the Universities of Chicago, Essex, Cambridge and Haifa, and the 1996 SEDC conference in Mexico City. 
This paper develops a model where metal coins are used as media of exchange, and uses the model to analyze two closely related questions in monetary economics: What are the conditions under which Gresham's Law holds? And, what are the mechanics of a debasement, an operation in which the metallic content of coins is lowered?

Gresham's Law, as it is commonly stated, asserts that bad money drives out good money. This is usually taken to mean that when two similar commodity monies compete, and one is in some sense inferior to the other, the inferior money will circulate and the superior money will not, but will instead be hoarded or shipped abroad. It is invoked in a variety of contexts, such as, for example, competition between light and heavy coins of a given type, or between coins of different metals like gold and silver. Despite it being one of the most generally accepted and frequently cited propositions in economics, we think that existing theoretical analyses of Gresham's Law are lacking, for reasons discussed below. ${ }^{1}$

Debasements have been observed for centuries and were actually quite common in medieval and modern European economies. The monetary system of that time consisted of metal coins (gold and silver) produced by mints under the direct control of sovereigns. Individuals could bring metal to the mint to be made into new coins of the same metal. This was costly, because the total metal content of the new coins returned was less than had been brought in, the difference being kept as seigniorage. In normal times the mint produced coins of a certain type, minting volumes were relatively small, and minting generated little revenue. When the currency was debased, however, the mint provided individuals the opportunity to voluntarily bring in old coins and receive new lighter coins in return. Typically, the seigniorage rate was also increased, sometimes substantially. Following debasements, minting volumes increased markedly and, combined with increased seigniorage rates, generated substantial revenue. Minting volumes were not so large as to remint the entire money supply, however, so that after a debasement heavy and light coins

\footnotetext{
1 Moreover, its empirical validity is questionable, or at least seems to depend on circumstances. Laughlin (1903, 423-28), describes a variety of instances in which Gresham's Law appears to work, while Rolnick and Weber (1986) describe several examples that seem to violate it, although Greenfield and Rockoff (1995) dispute these examples. De Roover (1949, 93) discusses the misattribution of the Law to the 16th century English banker Thomas Gresham, and remarks: "Gresham, consequently, does not state that bad money necessarily drives out good. On the contrary, he shows that bad money may be greatly overvalued and will not drive out the better coins, provided that the baser coins are issued only in limited quantity and not in excess of the needs of trade."
} 
circulated concurrently. ${ }^{2}$

Both the operation of Gresham's Law and the debasement facts are difficult to understand if we approach commodity money from the perspective of standard price theory and assume that coins derive their value from their intrinsic metallic content (something called circulation by weight). Rolnick and Weber (1986) question Gresham's Law on the following ground: If there exist two coins with different metallic content, why shouldn't both circulate at an exchange rate that reflects their relative intrinsic contents? Rolnick, Velde, and Weber (1996) argue that debasements constitute a similar puzzle: Why would individuals voluntarily bring in old coins for reminting after a debasement if money is valued by its metallic content? There seems to be no incentive to do so, especially given the high seigniorage rates.

Two approaches have been adopted in the literature. The first, which has been used to answer both questions, is to posit a fixed exchange rate between the various competing monies, something called circulation by tale. ${ }^{3}$ The origin of this fixed rate is sometimes thought to be legal restrictions, such as legal tender laws, or "conventions arising out of habit or ignorance." Examples of this approach are the models of commodity money in Sargent and Wallace (1983) and Sargent and Smith (1995), models that under some circumstances are able to generate outcomes consistent with Gresham's Law and debasement experiences. But circulation by tale does not arise endogenously in these models; it is simply imposed. The "conventions arising out of habit or ignorance" are not formalized; the alternative, legal restrictions, raises problems of credibility in medieval and early modern economies, where the powers of enforcement by the sovereign would not have been sufficient to enforce circulation by tale. ${ }^{4}$ Moreover, and this is critical, circulation by

2 Rolnick, Velde, and Weber (1996) document these facts for medieval France and England. A few details are as follows: Between 1285 and 1490, France had 123 debasements of silver coins, 112 of more than 5 percent, with the highest being 50 percent. France also had 64 gold debasements, 48 of more than 5 percent. In normal years, seigniorage was less than 5 percent of government revenue, but in debasement years it could be as high as 50 percent due to increases in both seigniorage rates and mint activity. England had a comparably stable monetary policy until the Great Debasement of Henry VIII, when silver or gold were debased 10 times and the pound sterling lost 83 percent of its metallic content between 1542 and 1551. During this period, seigniorage, which was typically less than 2 percent, rose to as high as 57 percent of government revenue.

3 One view is that this is a necessary condition for the empirical applicability of Gresham's Law. For example, Friedman and Schwartz $(1963,27 n)$ state that "Gresham's Law, that cheap money drives out dear money, applies only when there is a fixed rate of exchange between the two."

4 Miskimin (1987) notes: "[Gresham's Law] assumes that the government possesses enough political 
tale is not readily observed in the historical record: for some types of money, especially relatively valuable ones like gold coins, it is flatly contradicted, while for others the evidence is mixed to say the least (see Rolnick, Velde, and Weber 1996).

The second approach to modeling Gresham's Law is to try to explain the departure from standard price theory by postulating some degree of incomplete information about the objects used as money, following the insight of Akerlof (1970) linking the operation of Gresham's Law to a 'lemons' problem. ${ }^{5}$ Aiyagari (1989) and Williamson (1992) both use this approach in overlapping generations frameworks. In Aiyagari (1989), the distribution of assets with different returns is exogenous, and buyers cannot distinguish them. In equilibrium all assets trade at the same price, and changes in the exogenous distribution lead to an increase in the velocity of low-return assets, a phenomenon he associates with Gresham's Law. In Williamson (1992), a subset of agents have the ability to make highreturn or low-return investments and issue bank notes which cannot be distinguished. Absent regulation only bad money is issued, an outcome he associates with Gresham's Law. Banerjee and Maskin (1996) discuss a model with centralized markets for each individual good but assume that each trader is unable to distinguish the quality of some goods. In equilibrium, the low-quality variety of only one type of good is used as money.

The models of Banerjee and Maskin (1996) and Williamson (1992) lead to the prediction that only bad money is ever used; thus, they do not address the observed coexistence of different currencies. Aiyagari (1989) also captures the basic 'lemons' insight, but, in his own words, his model "is not designed to address questions regarding the provision and maintenance of commodity money." We conclude that existing models that have been applied to Gresham's Law and debasements are not well suited to deal with the issue of which objects circulate as money, cannot deliver the concurrent circulation of different monies in equilibrium, and therefore cannot be used to study the endogenous determination of the supply of money.

In this paper, we develop a search-based (or random-matching) model in which a

force to insist upon the legal tender value of the coinage and to decree circulation at par. There is, however, substantial evidence that neither the French nor the English monarchies gained this power until the end of the middle ages."

5 Actually, Akerlof distinguished the Lemons Principle from Gresham's Law because, in his reading, the latter applies when both parties know the quality of the money. 
commodity money potentially derives value beyond its intrinsic worth from its role as a medium of exchange that helps mitigate a double coincidence of wants problem. This is, of course, a common feature in models of commodity money (see, for example, the survey by Ostroy and Starr 1990). With regard to this literature, our model is closest to the one in Kiyotaki and Wright (1989). However, in order to address the substantive issues that concern us, in this paper, we make several key changes to that model.

First, we assume that most of the objects in the model are nonstorable, which makes it far easier to determine which, if any, ends up serving as money. In fact, by construction the media of exchange here will necessarily be metal coins, although these coins will come in different weights and it will be determined endogenously whether heavy, light, or both circulate as money. Second, we assume that consumption goods are divisible (rather than indivisible, as in all of the the early search-based models of commodity money), and we employ bilateral bargaining to determine prices. In this way we can let the model determine whether heavy and light coins circulate by weight or by tale. And, third, we also introduce private information, by assuming that in some bilateral meetings sellers are not able to distinguish between various types of coins. This is the ingredient that potentially allows for the simultaneous circulation of coins of different weights at prices that do not necessarily reflect their metallic content, and also potentially provides an incentive for some agents to bring coins to the mint despite the loss in intrinsic content that this entails. In contrast with the earlier models of Gresham's Law cited above, we allow for the possibility that a fraction of sellers are informed. This distinction is crucial, for example with respect to Aiyagari (1989), where the centralized trading requires that all buyers be uninformed, lest prices reveal the missing information immediately. ${ }^{6}$

The rest of the paper proceeds as follows: Section 1 presents the basic model. Section 2 defines and characterizes equilibrium and discusses Gresham's Law. Section 3

\footnotetext{
6 Technically, the model in this paper has much in common with the search-based models of fiat money, such as Kiyotaki and Wright (1991, 1993); however, the coins here are distinctly commodity and not fiat money in that they have intrinsic worth that depends on their weight. Bargaining was first introduced into search-based models of money by Shi (1995) and Trejos and Wright (1995). The private information set-up is similar to the fiat money model in Williamson and Wright (1994) and the extensions by Trejos $(1994,1996)$ and Kim (1996), although those papers are concerned with private information about consumption goods and not the medium of exchange, and also the commodity money models in Cuadras-Morató (1994) and Li (1995).
} 
analyzes debasements. And in Section 4 we conclude. Proofs of many technical results are contained in the Appendix.

\section{The Basic Model}

To generate an interesting role for currency in the model, we begin with a version of the standard specification for specialization in the search-based literature on money. There are $I \geq 3$ types of consumption goods. There is a $[0,1]$ continuum of infinite-lived agents, with equal fractions of $I$ types who are specialists in production and consumption in the following sense: type $i$ only consumes good $i$ and only produces good $i+1$ (modulo $I$ ). This rules out a double coincidence of wants in any bilateral meeting and hence rules out direct barter. For simplicity, we also assume here that these goods are nonstorable, which means that they must be produced and consumed simultaneously, and hence they cannot serve as commodity money. Below we introduce metal coins to play that role.

The above consumption goods are perfectly divisible. Each agent derives utility $u(q)$ from consuming $q$ units of his consumption good and derives disutility $c(q)$ from producing $q$ units of his production good. We assume $u(0)=0, u^{\prime}(q)>0, u^{\prime}(0)=\infty$, and $u^{\prime \prime}(q)<0$. Also, there is a unique $\hat{q}>0$ such that $u(\hat{q})=\hat{q}$. Notice that $u(q)>q$ if and only if $q<\hat{q}$. With no loss in generality, we can normalize $c(q)=q$ as long as we also renormalize $u(q)$ (in what follows, this merely amounts to having agents bargain over utils rather than physical quantities of output). Agents discount the future at rate $r>0$.

In addition to these consumption goods, there are other objects called metal coins that are storable and therefore can potentially serve as money. Initially, $M$ agents are endowed with one unit each of these objects. Coins come in two varieties: heavy $(H)$ and light $(L)$. Coins of type $H$ have greater intrinsic content (that is, they are heavier) than coins of type $L$ in a sense to be made precise below. Let $M_{j}$ be the measure of agents endowed with coins of type $j$, so that $M_{H}+M_{L}=M$. We call agents with money buyers and those without money sellers.

Agents meet bilaterally according to an anonymous random-matching process with arrival rate $\alpha$; thus, $\alpha / I$ is the probability per unit time that a buyer meets a seller who 
produces his consumption good, and also the probability per unit time that a seller meets a buyer who consumes his production good. In any such meeting, the buyer may or may not offer to trade his money for some amount of output to be determined endogenously. It is assumed that buyers always trade the whole unit and not fractional amounts of their money (say, because the coins are indivisible). It is also assumed that buyers never trade with other buyers (say, because except for those who initially begin as sellers, agents cannot produce until after they consume). This means that the aggregate distribution of money holdings is constant: at every date, there are $M_{j}$ buyers each with a single coin of type $j$ and $N=1-M$ sellers with no money.

In this model, when two agents want to trade, $q$ is determined by a very simple bargaining process that gives the buyer all of the bargaining power. That is, the buyer gets to make a take-it-or-leave-it offer, and is therefore in a position to extract all of the gains from trade and make the seller indifferent between accepting and rejecting his offer. The model would be qualitatively similar if we adopted some other bargaining solution (such as the symmetric Nash solution, for example), but the gain in simplicity from assuming take-it-or-leave-it offers seems to make this a very sensible assumption for the purposes at hand.

The difference between coins of type $H$ and type $L$ is not necessarily easy to detect, as was often the case historically, even when weight was indicated in principle by markings on the coins. ${ }^{7}$ Following the literature cited in the Introduction, we model this by assuming that a buyer always knows the type of coin he holds, but in any meeting a seller can recognize the weight of a coin only with some probability $\theta$, where $0 \leq \theta \leq 1 .^{8}$ After a transaction takes place and the buyer has departed, the seller can then determine the weight of the coin if he did not know it before the transaction. A buyer always knows whether a seller can recognize the weight of his coin; he cannot convince the seller of it when the seller is uninformed.

\footnotetext{
7 Cipolla $(1956,25)$ comments on these difficulties: "The maintenance of stable fineness was very important for the destiny of a coin and this importance was in direct correlation to the difficulty of ascertaining the fineness at the moment of payment."

8 These assumptions are meant to capture the idea that one may not always be able to verify a coin's true content, say, because one may not always have readily available one's scale or touchstone. We could have alternatively assumed that different agents have permanently different abilities to recognize weight, but giving all sellers the same random chance of recognizing weight in any given meeting actually simplifies the analysis.
} 
Our objective is to see if these coins circulate as commodity money and at what prices. What makes them commodity money? In this paper, we do not assume that the coins are consumed by the agents. Rather, we assume that a holder of a coin of type $j$ derives a constant utility flow $\gamma_{j}$, where $\gamma_{H} \geq \gamma_{L}>0$. This could be interpreted either as the utility one gets from possession of the metal per se, or as a reduced form for a more complicated story. One such story is as follows: Agents also consume a good which is provided by traders from outside the economy. There is a constant exogenous probability of meeting such a trader. Moreover, international trade requires the use of metal money, and coins necessarily go by weight. To maintain a constant stock of coins, we can think of agents as also exporting some good, and as trade being balanced so that coins return to the economy under study. ${ }^{9}$

What does it mean here for a coin to circulate? Given our bargaining solution, sellers are always willing to trade (this is the convenience of the assumption that buyers get to make take-it-or-leave-it offers). However, since a seller who recognizes the weight of a coin is presumably willing to trade at a different price than one who does not, buyers may not necessarily want to trade with every seller they meet. Indeed, since holding a coin yields a flow utility payment, some buyers may not want to trade with any sellers. Let $\lambda_{i j}$ be the probability that a buyer with a coin of type $i$ wants to trade with a seller who is of type $j$, where $j=K$ means the weight is known and $j=U$ means the weight is unbeknownst to the seller. If $\lambda_{i j}=1$, the buyer prefers to trade; if $\lambda_{i j}=0$, the buyer prefers not to trade; and if $\lambda_{i j}=\Phi$, the buyer is indifferent, where $\Phi$ is our notation for some point in the open interval $(0,1)$ (that is, $\lambda_{i j}=\Phi$ means that buyers randomize or, equivalently, that some buyers trade and others do not). Coins of type $i$ circulate in this economy if and only if $\lambda_{i j}>0$ for some $j .{ }^{10}$

9 Under either interpretation, the utility function is assumed to be additively separable and linear in the imported good or the utility of holding metal, so that we can use utils and quantities of metal interchangeably.

10 We do not have to describe minting until the section on debasements, since it is assumed for now that the stock of money is fixed, but it would be possible in principle to generate a role for the mint even without debasements by assuming that the coins depreciate or wear out over time. 


\section{Equilibrium and Gresham's Law}

Let $q_{j}$ be the amount of output a buyer of type $j \in\{H, L\}$ can get from an informed seller, and let $\bar{q}$ be the amount of output a buyer can get from an uninformed seller, which obviously cannot depend on the type of coin the buyer is holding. Also, let $V_{j}$ be the value function of a buyer with a coin of type $j \in\{H, L\}$, and let $V_{0}$ be the value function of a seller. ${ }^{11}$

For a seller, Bellman's equation is:

$$
\begin{aligned}
V_{0}=\frac{1}{1+r}\{ & \left(1-\frac{\alpha}{I} M\right) V_{0} \\
& +\frac{\alpha}{I} \theta M_{H}\left[\lambda_{H K}\left(V_{H}-q_{H}\right)+\left(1-\lambda_{H K}\right) V_{0}\right] \\
& +\frac{\alpha}{I} \theta M_{L}\left[\lambda_{L K}\left(V_{L}-q_{L}\right)+\left(1-\lambda_{L K}\right) V_{0}\right] \\
& +\frac{\alpha}{I}(1-\theta) M_{H}\left[\lambda_{H U}\left(V_{H}-\bar{q}\right)+\left(1-\lambda_{H U}\right) V_{0}\right] \\
& \left.+\frac{\alpha}{I}(1-\theta) M_{L}\left[\lambda_{L U}\left(V_{L}-\bar{q}\right)+\left(1-\lambda_{L U}\right) V_{0}\right]\right\} .
\end{aligned}
$$

In words, $V_{0}$ measures expected utility looking forward to next period, which is discounted by $r$. With probability $1-\alpha M / I$, the seller does not meet someone who has money and consumes the good the seller produces (since $\alpha / I$ is the probability of meeting the right type of consumer and $M$ is the probability they have money), in which case he must remain a seller one more period, and this conveys value $V_{0}$. With probability $\alpha \theta M_{H} / I$ he meets someone who consumes his good and has a heavy coin that is recognized, in which case with probability $\lambda_{H K}$ there is a trade, which conveys value $V_{H}-q_{H}$, and with probability $1-\lambda_{H K}$ there is no trade, which conveys value $V_{0}$. The remaining terms have similar interpretations.

A buyer's best take-it-or-leave-it offer makes the seller indifferent between accepting and rejecting, and therefore satisfies $V_{j}-q_{j}=V_{0}$ when the seller is informed and satisfies

11 The value functions, which measure maximum expected lifetime utility, are indexed by the agent's current state (whether he is a buyer with coin $H$, a buyer with coin $L$, or a seller) but not by his consumption-production type. Those types were introduced only to preclude direct barter, and here we will only consider symmetric equilibria where all types use the same strategy and receive the same payoff. Also, $V_{0}$ is not indexed by whether the seller can or cannot identify weight, since the value functions are computed before meetings take place. 
$\pi V_{H}+(1-\pi) V_{L}-\bar{q}=V_{0}$ when the seller is uninformed, where $\pi$ is the probability that the buyer has a heavy coin given that he wants to trade:

$$
\pi=\frac{\lambda_{H U} M_{H}}{\lambda_{H U} M_{H}+\lambda_{L U} M_{L}} .
$$

Inserting these values for $q_{H}, q_{L}$, and $\bar{q}$ into (1) yields $V_{0}=0$, which is natural since the seller never gets any of the gains from trade. This, in turn, allows us from now on to identify $V_{j}=q_{j}$; that is, the lifetime expected utility of having a coin is simply equal to its value in exchange. Moreover,

$$
\bar{q}=\pi q_{H}+(1-\pi) q_{L},
$$

so that $\bar{q}$ is an average of $q_{H}$ and $q_{L}$ with weights determined by the objective frequencies of receiving heavy and light coins.

We can now write Bellman's equation for a buyer with a coin of type $j \in\{H, L\}$ as follows:

$$
\begin{aligned}
V_{j}=\frac{1}{1+r}\{ & \frac{\alpha}{I} N \theta \max _{\lambda_{j K}}\left[\lambda_{j K} u\left(q_{j}\right)+\left(1-\lambda_{j K}\right) V_{j}\right] \\
& \left.+\frac{\alpha}{I} N(1-\theta) \max _{\lambda_{j U}}\left[\lambda_{j U} u(\bar{q})+\left(1-\lambda_{j U}\right) V_{j}\right]+\left(1-\frac{\alpha}{I} N\right) V_{j}+\gamma_{j}\right\} .
\end{aligned}
$$

The first and second terms on the right-hand side are the expected payoffs from meeting informed and uninformed sellers, and choosing the probability of trade in each case; the third term is the expected payoff from not meeting a seller; and the final term $\gamma_{j}$ is the commodity value to holding the coin, which the buyer receives in all cases. ${ }^{12}$ Multiplying by $(1+r)$ and rearranging yields the flow version of Bellman's equation often seen in search theory:

$$
r V_{j}=\frac{\alpha}{I} N \theta \max _{\lambda_{j K}} \lambda_{j K}\left[u\left(q_{j}\right)-V_{j}\right]+\frac{\alpha}{I} N(1-\theta) \max _{\lambda_{j U}} \lambda_{j U}\left[u(\bar{q})-V_{j}\right]+\gamma_{j}
$$

12 Under the interpretation that $\gamma_{j}$ is a reduced form for trading with foreign agents, (5) seems to indicate that the money holder simultaneously imports and exports, since after receiving $\gamma_{j}$, he keeps his coin. It is merely a change in notation to alternatively assume that when he imports, he switches from buyer to seller, and simultaneously (in steady state) some other agent switches from seller to buyer by exporting (assuming that foreign buyers, just like domestic buyers, get to make take-it-or-leave-it offers). 
Finally, inserting the bargaining solution $V_{j}=q_{j}$ and letting $\beta=\alpha N / I$ denote the effective arrival rate (the probability of meeting someone who is a seller and produces the right good), we arrive at

$$
r q_{j}=\beta \theta \max _{\lambda_{j K}} \lambda_{j K}\left[u\left(q_{j}\right)-q_{j}\right]+\beta(1-\theta) \max _{\lambda_{j U}} \lambda_{j U}\left[u(\bar{q})-q_{j}\right]+\gamma_{j} .
$$

Equation (5) describes the value of $q=\left(q_{H}, q_{L}\right)$ in terms of $\bar{q}$, which is simply a weighted average given by (2), exogenous parameters, and the endogenous vector $\lambda=$ $\left(\lambda_{H K}, \lambda_{L K}, \lambda_{H U}, \lambda_{L U}\right)$. The latter, which determines when coins circulate, must satisfy the following incentive or best response conditions:

$$
\begin{aligned}
& \lambda_{L K}=\left\{\begin{array}{l}
0 \\
\Phi \\
1
\end{array} \quad \text { as } u\left(q_{L}\right)-q_{L}\left\{\begin{array}{l}
<0 \\
=0 \\
>0
\end{array}\right.\right. \\
& \lambda_{L U}=\left\{\begin{array}{l}
0 \\
\Phi \\
1
\end{array} \quad \text { as } u(\bar{q})-q_{L} \quad\left\{\begin{array}{l}
<0 \\
=0 \\
>0
\end{array}\right.\right. \\
& \lambda_{H K}=\left\{\begin{array}{l}
0 \\
\Phi \\
1
\end{array} \text { as } u\left(q_{H}\right)-q_{H}\left\{\begin{array}{l}
<0 \\
=0 \\
>0
\end{array}\right.\right. \\
& \lambda_{H U}=\left\{\begin{array}{l}
0 \\
\Phi \\
1
\end{array} \text { as } u(\bar{q})-q_{H} \quad\left\{\begin{array}{l}
<0 \\
=0 \\
>0
\end{array}\right.\right.
\end{aligned}
$$

where we recall that $\Phi$ is our notation for some point in $(0,1)$. These conditions simply say that the buyer trades if it makes him strictly better off, does not trade if it makes him strictly worse off, and may randomize if he is indifferent.

An equilibrium in this economy can now be conveniently defined as a pair $(q, \lambda)$ satisfying Bellman's equation (5) and the incentive constraints (6); remaining variables, such as $\bar{q}$, can be recovered from other conditions when needed. To characterize the set of equilibria one proceeds as follows. Given $\lambda$, solve (5) for $q$ and find the set of parameter values such that (6) is satisfied; for these parameter values, $(q, \lambda)$ constitutes an equilibrium. It might appear that this is a lengthy exercise, because $\lambda$ can take on many different values; but the following preliminary lemmas dramatically reduce the number of possible cases. 
Lemma 1. In any equilibrium, $q_{H} \geq q_{L}$ with $q_{H}=q_{L}$ if and only if $\gamma_{H}=\gamma_{L}$.

Lemma 2. Equilibria with $\lambda_{H K}=\Phi, \lambda_{L K}=\Phi$, or $\lambda_{L U}=\Phi$ do not exist, except possibly for a set of measure zero in parameter space.

Lemma 1 verifies that heavy coins are more valuable than light coins in exchange, and they have the same value in exchange if and only if they have exactly the same weight. ${ }^{13}$ Lemma 2 holds for the following reason. In order for a buyer to be indifferent between trading and not trading in certain types of meetings, exogenous parameter values have to be just right. Hence, we ignore cases where $\lambda_{H K}, \lambda_{L K}$, and $\lambda_{L U}$ are not either 0 or 1 . Things are different for $\lambda_{H U}$, however. When a heavy coin holder meets an uninformed seller and decides whether to trade, he must consider $\bar{q}$, which depends on $\pi$, which itself depends on the probability of heavy coin holders trading with uninformed sellers. Therefore endogenous variables can potentially adjust to make a buyer with a heavy coin indifferent between trading and not trading with an uninformed seller. These considerations will also lead below to multiple equilibria for certain parameter values.

Given the above results, it turns out that all possible equilibria fall into one of four categories, each with its own economic interpretation. We now describe these four categories, and characterize the set of parameter values for which each exists.

1. No-Trade Equilibrium: $\left(\lambda_{L K}, \lambda_{L U}, \lambda_{H K}, \lambda_{H U}\right)=(0,0,0,0)$.

Suppose that $\lambda_{L K}=0$. Then is is easy to show that $\lambda=0 .{ }^{14}$ Hence, if light coins are not used to trade with informed sellers, then no coins are ever traded in this economy, and, depending on the interpretation, they are either hoarded or shipped abroad. We call this a no-trade equilibrium.

When will a no-trade equilibrium exist? Given $\lambda=0$, the solution to (5) is $q_{i}=\gamma_{i} / r$.

13 This is an important difference between commodity and fiat money. With two fiat monies which only differ in, say, color, both with $\gamma=0$, there are equilibria where they have different exchange values in equilibrium (see, for example, Shi 1995). In particular, one might have positive value and the other zero value in equilibrium, something that cannot happen with our commodity monies.

14 Recall that $\lambda_{L K}=0$ requires $u\left(q_{L}\right)<q_{L}$ (indifference being ruled out as nongeneric), which is equivalent to $q_{L}>\hat{q}$. By Lemma $1, q_{H} \geq \bar{q} \geq q_{L}$, and therefore we also have $u\left(q_{H}\right)<q_{H}$ and $u(\bar{q})<\bar{q} \leq q_{H}$, or $\lambda_{H K}=0$ and $\lambda_{H U}=0$. Finally, given $\lambda_{H U}=0$, we have $\pi=0$ and $\bar{q}=q_{L}$, and this implies $\lambda_{L U}=0$. 
In other words, when no trade is occurring, a buyer could deviate and trade a coin of type $i$ for $q_{i}=\gamma_{i} / r$. He will not deviate if the incentive constraint $u\left(q_{i}\right) \leq q_{i}$ holds for $i=1,2$. Hence, the no-trade equilibrium exists if and only if $\gamma_{L} / r \geq \hat{q}$. In other words, if coins have sufficient intrinsic value, they will not circulate. In Figure 1, in which we will eventually display all of the possible equilibria in $(r, \theta)$ space, the no-trade equilibrium exists to the left of the vertical line at the point corresponding to $r=\gamma_{L} / \hat{q}$ (which is $r=0.02$ for the parameter values used to construct the figure).

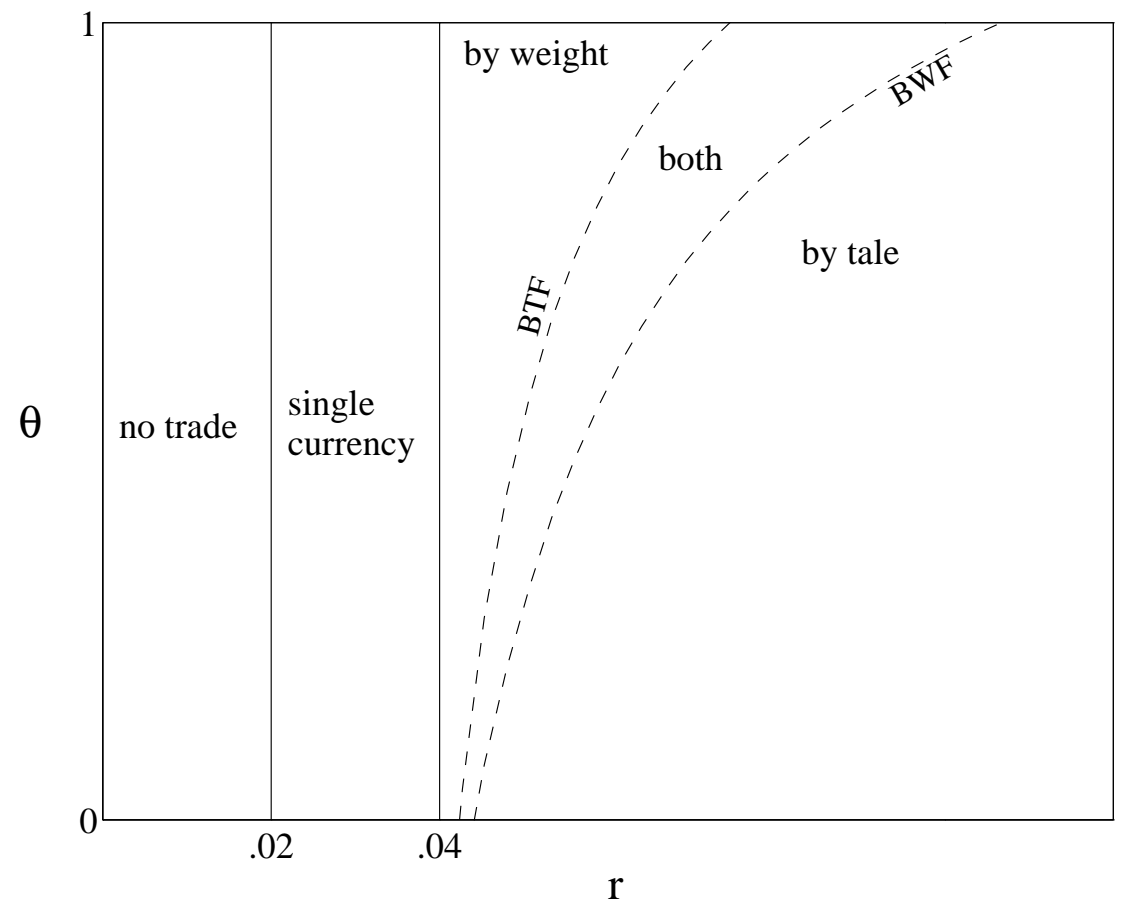

Figure 1: Equilibrium regions in $(r, \theta)$ space (BWF and BTF indicate the by-weight and by-tale frontiers).

Having exhausted the possible cases with $\lambda_{L K}=0$, we now assume $\lambda_{L K}=1$. It is easy to show that this implies $\lambda_{L U}=1 .{ }^{15}$ Hence, if light coins are traded to informed

\footnotetext{
15 If $\lambda_{L K}=1$ then $u\left(q_{L}\right)>q_{L}$, or $q_{L}<\hat{q}$. By Lemma $1, \bar{q} \geq q_{L}$, and $u(\bar{q}) \geq u\left(q_{L}\right)>q_{L}$. Therefore, $\lambda_{L U}=1$.
} 
sellers, they are also traded to uninformed sellers. Now $\lambda_{H K}$ is either 0 or 1 , and we consider each in turn.

2. Single-Currency Equilibrium: $\left(\lambda_{L K}, \lambda_{L U}, \lambda_{H K}, \lambda_{H U}\right)=(1,1,0,0)$.

Given $\lambda_{H K}=0$, it is easy to show $\lambda_{H U}=0 .^{16}$ Thus, when heavy coins are not used in trade with informed sellers, they are never traded. We call this a single-currency equilibrium, because only light coins circulate while heavy coins are hoarded or shipped abroad.

When does the single-currency equilibrium exist? The incentive constraints in this case require $q_{L} \leq \hat{q}$ and $q_{H} \geq \hat{q}$. Now (5) implies

$$
\begin{aligned}
r q_{L} & =\beta\left[u\left(q_{L}\right)-q_{L}\right]+\gamma_{L}, \\
r q_{H} & =\gamma_{H} .
\end{aligned}
$$

It is easy to show that the incentive conditions are satisfied if and only if $\gamma_{L} / \hat{q} \leq r \leq$ $\gamma_{H} / \hat{q}{ }^{17}$ Hence, the single-currency equilibrium exists if the heavy coins are too intrinsically valuable to be used as money, while the light coins are not. In Figure 1, the single-currency equilibrium lies between the two vertical lines corresponding to $r=\gamma_{L} / \hat{q}$ and $r=\gamma_{H} / \hat{q}$ (0.02 and 0.04 respectively).

The only remaining possibilities involve $\lambda_{L K}=\lambda_{L U}=\lambda_{H K}=1$. We partition these cases into those with $\lambda_{H U}=0$ and those with $\lambda_{H U}>0$.

3. By-Weight Equilibrium: $\left(\lambda_{L K}, \lambda_{L U}, \lambda_{H K}, \lambda_{H U}\right)=(1,1,1,0)$.

If $\lambda_{H U}=0$, then $\pi=0$ and $\bar{q}=q_{L}$. Thus, light coins are traded always and at the same price in all transactions, $q_{L}$, while heavy coins are traded if and only if the seller is informed at the price $q_{H}$. We call this an equilibrium with circulation by weight, because an observer of the economy would distinguish two types of coins, each circulating

16 If $\lambda_{H K}=0$, then $u\left(q_{H}\right)<q_{H}$, or $q_{H}>\hat{q}>q_{L}$. By Lemma $1, \bar{q} \leq q_{H}$, so that $u(\bar{q}) \leq u\left(q_{H}\right)<q_{H}$ and $\lambda_{H U}=0$.

17 First, $\gamma_{H} / r>\hat{q}$ implies $q_{H}=\gamma_{H} / r>u\left(q_{H}\right)$ by definition of $\hat{q}$. As for the other incentive constraint, suppose it did not hold and $q_{L}$ defined by $(7 \mathrm{a})$ is such that $u\left(q_{L}\right)<q_{L}$. In that case, $q_{L}=\gamma_{L} / r+\beta\left[u\left(q_{L}\right)-q_{L}\right] / r<\gamma_{L} / r<\hat{q}$, and therefore $u\left(q_{L}\right)>q_{L}$, which is a contradiction. 
at its own price, which reflects its intrinsic content. However, we will show below that the exchange value of a coin is not proportional to its metallic content, and so coins do not trade exactly by weight even with informed sellers (although they do with foreign sellers, under the appropriate interpretation of $\gamma_{H}$ and $\gamma_{L}$ ).

In a by-weight equilibrium, when a holder of a heavy coin meets a seller who cannot appreciate its quality, he prefers to wait for an informed seller rather than trade now for $\bar{q}=q_{L}$. Intuitively, we would therefore expect this equilibrium to exist if agents are patient or the fraction of informed sellers is high. More formally, in this case (5) implies

$$
\begin{aligned}
& r q_{L}=\beta\left[u\left(q_{L}\right)-q_{L}\right]+\gamma_{L}, \\
& r q_{H}=\beta \theta\left[u\left(q_{H}\right)-q_{H}\right]+\gamma_{H} .
\end{aligned}
$$

The incentive constraints require $u\left(q_{L}\right) \geq q_{L}, u\left(q_{H}\right) \geq q_{H}$, and $u\left(q_{L}\right) \leq q_{H}$. The first two are easily shown to hold if and only if $r \geq \gamma_{H} / \hat{q}$. Now define the by-weight frontier $\theta=$ $f_{w}(r)$ as the set of points in $(r, \theta)$ space such that the pair $q_{H}=q_{H}(r, \theta)$ and $q_{L}=q_{L}(r, \theta)$ that solves (8a) and (8b) satisfies the remaining incentive constraint with equality. Note that $\theta=f_{w}(r)$ is a (single-valued) function. Then this equilibrium exists for points above the by-weight frontier in $(r, \theta)$ space in Figure 1.

A by-weight equilibrium delivers the following version of Gresham's Law. In the absence of light coins, heavy coins would be used in all trades. ${ }^{18}$ But when light coins are present, heavy coins do not trade in meetings with uninformed sellers. Heavy coins are not completely driven out of circulation, of course, since they are still used in trades with informed sellers (and also with foreigners). In any case, it is the presence of light coins that limits, if not eliminates, the circulation of heavy coins in this equilibrium, because it is the presence of light coins that reduces $\bar{q}$. By way of contrast, in the single-currency equilibrium heavy coins do not circulate domestically at all, but they would not circulate even if there were no light coins (that is, even if $M_{L}=0$ and $\bar{q}=q_{H}$ ).

4. By-Tale Equilibrium: $\left(\lambda_{L K}, \lambda_{L U}, \lambda_{H K}, \lambda_{H U}\right)=(1,1,1,+)$.

We call the remaining possibility, with $\lambda_{H U}>0$, circulation by tale because, at least in some trades, a light coin buys as much as a heavy coin. More precisely, under

18 To see this, consider Eq. (8) with $\gamma_{L}=\gamma_{H}$ and $\theta=1$; an equilibrium exists for $r \geq \gamma_{H} / \hat{q}$. 
circulation by tale, $q_{L}<\bar{q}<q_{H}$, so that buyers obtain a premium on heavy coins and a discount on light coins with informed sellers, and they trade either coin at the same price with uninformed sellers. This feature is observed in both the pure strategy case where $\lambda_{H U}=1$ and in the mixed strategy case where $0<\lambda_{H U}<1$. For this reason, we consider these two types of equilibria to be variants of circulation by tale.

Consider first the pure strategy case, with $\lambda_{H U}=1$. Intuitively, for a heavy coin holder to spend it when the seller is uninformed, he must be impatient or the fraction of informed sellers must be low. More rigorously, note that (5) implies

$$
\begin{aligned}
& r q_{L}=\beta \theta\left[u\left(q_{L}\right)-q_{L}\right]+\beta(1-\theta)\left[u(\bar{q})-q_{L}\right]+\gamma_{L} \\
& r q_{H}=\beta \theta\left[u\left(q_{H}\right)-q_{H}\right]+\beta(1-\theta)\left[u(\bar{q})-q_{H}\right]+\gamma_{H},
\end{aligned}
$$

where $\bar{q}=\left(M_{H} q_{H}+M_{L} q_{L}\right) / M$. The incentive constraints require $q_{L} \leq \hat{q}, q_{H} \leq \hat{q}$, and $u(\bar{q}) \geq q_{H}$, and one can show that the final constraint is the binding one. Following the analysis of the by-weight equilibrium, define the by-tale frontier $\theta=f_{t}(r)$ as the set of points in $(r, \theta)$ space such that the pair $q_{H}=q_{H}(r, \theta)$ and $q_{L}=q_{L}(r, \theta)$ that solves (9a) and $(9 \mathrm{~b})$ satisfies the relevant incentive constraint with equality. Note that $\theta=f_{t}(r)$ is also a (single-valued) function. Then the by-tale equilibrium exists below the by-tale frontier in $(r, \theta)$ space (see Figure 1).

The following result says that the by-tale frontier always lies above the by-weight frontier; that is, the existence regions for the two equilibria necessarily overlap, as shown in Figure 1.

Lemma 3. The curve $\theta=f_{t}(r)$ lies above the curve $\theta=f_{w}(r)$ in $(r, \theta)$ space.

Moreover, we now show that there also exists a unique mixed strategy by-tale equilibrium, with $\lambda_{H U}=\Phi$, in the region where the two pure strategy equilibria coexist. In such an equilibrium, (5) implies

$$
\begin{aligned}
& r q_{L}=\beta \theta\left[u\left(q_{L}\right)-q_{L}\right]+\beta(1-\theta)\left[u(\bar{q})-q_{L}\right]+\gamma_{L} \\
& r q_{H}=\beta \theta\left[u\left(q_{H}\right)-q_{H}\right]+\gamma_{H},
\end{aligned}
$$


where $u(\bar{q})=q_{H}$ (holders of heavy coins are indifferent between trading and not trading with uninformed sellers), and

$$
\bar{q}=\frac{\Phi M_{H} q_{H}+M_{L} q_{L}}{\Phi M_{H}+M_{L}}
$$

for some $\Phi \in(0,1)$. Equation $(10 \mathrm{~b})$ determines $q_{H}$. Then, if we insert $u(\bar{q})=q_{H}$ into (10a), $q_{L}$ is determined. It remains to choose $\Phi \in(0,1)$ so that $u(\bar{q})=q_{H}$. At $\Phi=0$ we have $u(\bar{q})<q_{H}$, at $\Phi=1$ we have $u(\bar{q})>q_{H}$, and $\bar{q}$ is monotone in $\Phi$. Hence, there is a unique $\Phi \in(0,1)$ that satisfies $u(\bar{q})=q_{H}$.

In the pure strategy by-tale equilibrium, trades with uninformed sellers always take place, and those sellers produce the same amount of output, $\bar{q}$, for both types of coins. In the mixed strategy case, the only difference is that buyers with a heavy coin sometimes pass up trades with uninformed sellers. In either case, we observe the concurrent circulation of light and heavy coins, sometimes going for the same price and sometimes going at different prices. Depending on how close $\theta$ is to 0 or 1 (that is, depending on how hard it is to verify weight), the proportion of by-tale trades can be arbitrarily high.

Although the mixed strategy equilibrium shares with the pure strategy by-tale equilibrium the feature that heavy and light coins sometimes trade at the same price, the former also shares some properties with the by-weight equilibrium. In particular, Gresham's Law applies in the mixed strategy by-tale equilibrium, although not to the same extent that it applies in the by-weight case, and for the same reason: the presence of light coins, by reducing $\bar{q}$, makes buyers with heavy coins disinclined to trade in at least some meetings with uninformed sellers. In the region where the different equilibria coexist, Gresham's Law applies to a greater or lesser extent depending on which equilibrium we are in. Hence, whether bad money drives out good depends at least to some extent on beliefs and not exclusively on fundamentals. ${ }^{19}$

The reason for the multiplicity in the model is something to which we alluded earlier: when more heavy coin holders trade with uninformed sellers, uninformed sellers rationally

19 Given the insistence of Friedman and Schwartz (1963, 27n) on a fixed exchange rate for the operation of Gresham's Law, it is interesting to note that, in this model, circulation by tale and Gresham's Law appear to be in some sense opposites. 
increase their expectation of receiving heavy coins, which improves the terms of trade and thereby provides greater incentive for buyers to spend their heavy coins. Moreover, when the different equilibria coexist, we can Pareto rank them, and we find that agents are worse off when Gresham's Law applies to a greater extent (intuitively, because fewer trades get realized).

Lemma 4. When the equilibria coexist, the pure strategy by-tale equilibrium Pareto dominates the mixed strategy by-tale equilibrium, which dominates the by-weight equilibrium.

Before proceeding we want to emphasize that commodity money, as its name suggests, is a hybrid of a commodity and money. One manifestation of this is that $q_{H} / q_{L} \leq \gamma_{H} / \gamma_{L}$, with strict inequality except in the no-trade equilibrium. ${ }^{20}$ This tells us that even in the by-weight equilibrium coins do not literally trade by weight: twice the metal yields less than twice the value in exchange, except in foreign trade. The reason is that, as long as coins circulate, they have value as media of exchange in addition to their intrinsic value as commodities. As a fraction of their total value $q$, the medium of exchange component is higher for light coins.

We summarize the main results of this section as follows:

Proposition 1. The possible equilibria, which exist in the regions shown in Figure 1, are as follows:

(1) a no-trade equilibrium where no coins circulate;

20 The statement is obvious in the no-trade and single-currency equilibria. For the other cases, we use the inequality $q_{H} u\left(q_{L}\right)-\theta q_{L} u\left(q_{H}\right)>0$, which follows from concavity. In the by-weight equilibrium, (8) implies

$$
\frac{q_{H}}{q_{L}}=\frac{\beta \theta u\left(q_{H}\right)+\gamma_{H}}{N u\left(q_{L}\right)+\gamma_{L}}
$$

which leads to $\gamma_{H} q_{L}-\gamma_{L} q_{H}=\beta\left[q_{H} u\left(q_{L}\right)-\theta u\left(q_{H}\right) q_{L}\right]>0$, and therefore $\gamma_{H} / \gamma_{L}>q_{H} / q_{L}$. In a (pure or mixed strategy) by-tale equilibrium, (9) implies

$$
\frac{q_{H}}{q_{L}}=\frac{\beta \theta u\left(q_{H}\right)+\beta(1-\theta) u(\bar{q})+\gamma_{H}}{\beta \theta u\left(q_{L}\right)+\beta(1-\theta) u(\bar{q})+\gamma_{L}}
$$

which leads to $\gamma_{H} q_{L}-\gamma_{L} q_{H}=\beta \theta\left[q_{H} u\left(q_{L}\right)-\theta u\left(q_{H}\right) q_{L}\right]+N(1-\theta) u(\bar{q})\left(q_{H}-q_{L}\right)>0$, and therefore to the same conclusion. 
(2) a single-currency equilibrium where light coins circulate but heavy coins do not;

(3) a by-weight equilibrium where heavy and light coins always trade at different prices, and heavy-coin holders never trade with uninformed sellers (a version of Gresham's Law);

(4a) a pure strategy by-tale equilibrium where heavy and light coins sometimes trade at the same price, and holders of heavy coins always trade with uninformed sellers;

(4b) a mixed strategy by-tale equilibrium where heavy and light coins sometimes trade at the same price, and holders of heavy coins sometimes do and sometimes do not trade with uninformed sellers (a partial version of Gresham's Law).

We can use Figure 1 to provide more economic intuition about the existence of the different equilibria. ${ }^{21}$ Consider first a reduction in the rate of time preference, which moves us to the left in the figure and captures a reduction in search-type trading frictions. For large $r$, we must be in a by-tale equilibrium, which indicates that very impatient buyers are simply unwilling to wait for informed sellers. As $r$ decreases toward $\gamma_{H} / \hat{q}$, we eventually must switch to a by-weight equilibrium, where buyers do wait for informed sellers and heavy coins are at least partially withdrawn from circulation. As $r$ decreases further, first below $\gamma_{H} / \hat{q}$ and then below $\gamma_{L} / \hat{q}$, first heavy and then light coins drop out of circulation entirely.

Consider now how $\theta$, which measures information frictions, affects the set of equilibria. Figure 1 indicates that for $r$ sufficiently big or small, the type of equilibrium actually does not depend on $\theta$, while for intermediate values of $r$ it does. In this intermediate range, as $\theta$ rises from 0 to 1 , we necessarily move from the pure strategy by-tale equilibrium through the region of multiple equilibria to the by-weight equilibrium. In short, reducing either search or information frictions (moving to the northwest in the figure) makes it less likely that a by-tale equilibrium exists and more likely that Gresham's Law applies. $^{22}$

21 The figure was constructed for a parametric example with $u(q)=q^{\sigma}$, which implies $\hat{q}=1$, using $\sigma=0.7, \gamma_{L}=0.02, \gamma_{H}=0.04, M_{H}=0.2$, and $M_{L}=0.3$. The features of this example are true in the general case, with one exception: the by-weight and by-tale frontiers are not necessarily monotone.

22 The relative likelihood of a by-tale or by-weight equilibrium is also related to the degree of risk- 


\section{Debasement}

In this section we consider the effects of a debasement. Recall that, historically, a debasement was an offer by the mint to swap light for heavy coins. Now, clearly, no one would voluntarily trade a single heavy coin for a single light coin, since the former are more valuable, by Lemma 1 . Thus, the mint would have to offer a side payment of some sort. In practice, the side payment consisted of additional light coins; that is, the mint would give $n>1$ light coins for a heavy coin, although the total metallic content of the $n$ light coins would have to be less than the metallic content of a single heavy coin for seigniorage to be positive.

For reasons of tractability, we model things slightly differently by assuming that the side payment is in the form of real output that can be consumed immediately for an implied utility of $\xi$, and measure seigniorage in terms of $\xi$ relative to the difference in the metallic contents of the heavy and light coins (measured in the appropriate units). The advantage of this approach is that it keeps the total number of coins constant (thus setting aside effects due to increased liquidity), and, more importantly, implies that everyone continues to have either one coin or zero coins, whether they go to the mint or not. This allows us to avoid analyzing a model where agents can have more than one coin, which is much more complicated (see Green and Zhou 1995, Zhou 1995, Molico 1995, and Camera and Corbae 1995 for papers that analyze such models in an otherwise similar framework).

Thus, we start from a situation where there are $M$ heavy coins and no light coins in the economy, and we assume that $r>\gamma_{H} / \hat{q}$, so that the heavy coins circulate. Then, acting on behalf of the sovereign, we offer every agent with a heavy coin the opportunity

aversion. Take two polar cases: $u(q)=q$ (no risk-aversion) and $u(q)=1$ (extreme risk aversion). It is easy to see that the by-weight equilibrium always exists and the by-tale equilibrium never exists in the first case. Conversely, the by-tale equilibrium always exists and the by-weight equilibrium never exists in the second case. The by-tale equilibrium offers more opportunity for trade, since buyers never turn down opportunities to trade even with uninformed sellers, and therefore reduces the unconditional consumption risk borne by agents.

We can also ask how parameters affect prices in a given equilibrium. For example, in any equilibrium where both coins circulate, one can show $\partial q_{H} / \partial r<0$ and $\partial q_{L} / \partial r<0$. Hence, increasing search frictions reduces the exchange value of all coins. Also, in any equilibrium where both coins circulate, $\partial q_{H} / \partial \theta>0$. Hence, increasing information frictions reduces the exchange value of heavy coins. In the by-weight equilibrium, $\partial q_{L} / \partial \theta=0$; in the pure strategy by-tale equilibrium, $\partial q_{L} / \partial \theta<0$; and in the mixed strategy equilibrium by-tale equilibrium, $\partial q_{L} / \partial \theta>0$. Hence, the effect of information frictions on the exchange value of light coins depends on the type of equilibrium. 
to exchange it for a light coin plus the side payment $\xi$. The post-debasement mix between heavy and light coins depends on how many agents go to the mint, but it will always be the case that everyone continues to have either one coin or zero coins. Modeling a debasement in this way allows us to capture in a very simple way the following key features of debasements: metallic content is lowered; minting is voluntarily; and we potentially earn revenue, depending on the exogenous size of the side payment and on the endogenous decisions of private agents. ${ }^{23}$

Given $\xi$, we need to find values for $q, \lambda$, and now also $M_{L}$, which satisfy the equilibrium conditions in the previous section plus a condition determining the decision to go to the mint:

(i) $M_{L}=0$ if $q_{H}>\xi+q_{L}$;

(ii) $M_{L}=M$ if $q_{H}<\xi+q_{L}$;

(iii) $0<M_{L}<M$ implies $q_{H}=\xi+q_{L}$.

Three types of outcomes are a priori possible. The first is that no one goes to the mint and no light coins get into circulation $\left(M_{L}=0\right.$ and $\left.M_{H}=M\right)$. The second is that everyone goes to the mint and all heavy coins are withdrawn from circulation $\left(M_{L}=M\right.$ and $\left.M_{H}=0\right)$. The third is the case where agents are indifferent between a heavy coin and a light coin plus the side payment, some of them go to the mint and some of them do not, and both coins circulate in equilibrium $\left(0<M_{L}<M\right.$ and $\left.0<M_{H}<M\right)$. We now show that each type of equilibrium can exist for parameter values in a set of positive measure, and that the equilibrium is generically unique. We will also show that, at least when the frictions are serious (that is, for low enough values of $\theta$ or $r$ ), debasements will generate positive seigniorage revenue.

Consider first case (i), an equilibrium with no reminting. We need to check that an individual has no incentive to go to the mint, given that no one else goes. First note that

23 Note that we assume for simplicity that private agents can go to the mint instantaneously and at zero cost. A more complicated model could have private agents arriving at the mint randomly over time, which would mean that light coins trickle out over time and hence would require a non-stationary analysis. See Green and Weber (1995) for such an analysis with two different fiat monies. 
when $M_{L}=0$, a holder of heavy coin is always willing to trade with uninformed sellers, since they always offer $q_{H}$ for any coin and $u\left(q_{H}\right)>q_{H}$. Given this, if the individual keeps his heavy coin, he obtains the payoff $V_{H}=q_{H}$, where

$$
r q_{H}=\beta\left[u\left(q_{H}\right)-q_{H}\right]+\gamma_{H} .
$$

If he deviates and goes to the mint, he obtains the side payment $\xi$ plus the continuation payoff $V_{L}=q_{L}$, where

$$
r q_{L}=\beta \theta\left[u\left(q_{L}\right)-q_{L}\right]+\beta(1-\theta)\left[u\left(q_{H}\right)-q_{L}\right]+\gamma_{L}
$$

Let $\left(q_{H}, q_{L}\right)$ be the unique solution to (12), and let $\xi_{1}=q_{H}-q_{L}$. Then it is an equilibrium for no one to go to the mint if and only if the side payment is smaller than $\xi_{1}$.

Now consider case (ii), where everyone goes to the mint. An individual who does so obtains the side payment plus the continuation payoff $V_{L}=q_{L}$, where

$$
r q_{L}=\beta\left[u\left(q_{L}\right)-q_{L}\right]+\gamma_{L}
$$

If he deviates and keeps his heavy coin, he obtains $V_{H}=q_{H}$, where now

$$
r q_{H}=\beta \theta\left[u\left(q_{H}\right)-q_{H}\right]+\beta(1-\theta) \max _{\lambda_{H U}} \lambda_{H U}\left[u\left(q_{L}\right)-q_{H}\right]+\gamma_{H}
$$

This assumes that he will trade a heavy coin when he meets an informed trader (that is, $q_{H} \leq \hat{q}$ ), but allows him either to trade or not trade when he meets an uninformed trader (that is, it allows either a by-tale or a by-weight equilibrium). Proceeding as in the previous case, let $\xi_{2}$ be the difference between the values of $q_{H}$ and $q_{L}$ that solve (13). Then it is an equilibrium for everyone to go to the mint if and only if the side payment exceeds $\xi_{2}$.

We illustrate the properties of $\xi_{1}$ and $\xi_{2}$ as functions of $\theta$ in Figure 2, which is based on the following lemma.

Lemma 5. As functions of $\theta, \xi_{1}(\theta)$ and $\xi_{2}(\theta)$ are both upward-sloping, $\xi_{2}(1)=\xi_{1}(1)$, $\xi_{2}(0) \geq \xi_{1}(0)=\left(\gamma_{H}-\gamma_{L}\right) /(r+\beta)$, and $\xi_{2}(\theta)>\xi_{1}(\theta)$ for all $\theta \in(0,1)$.

A key part of this result is that there is a nonempty region where the side payment falls between $\xi_{1}$ and $\xi_{2}$, and in this region neither $M_{L}=0$ nor $M_{L}=M$ is an equilibrium. 


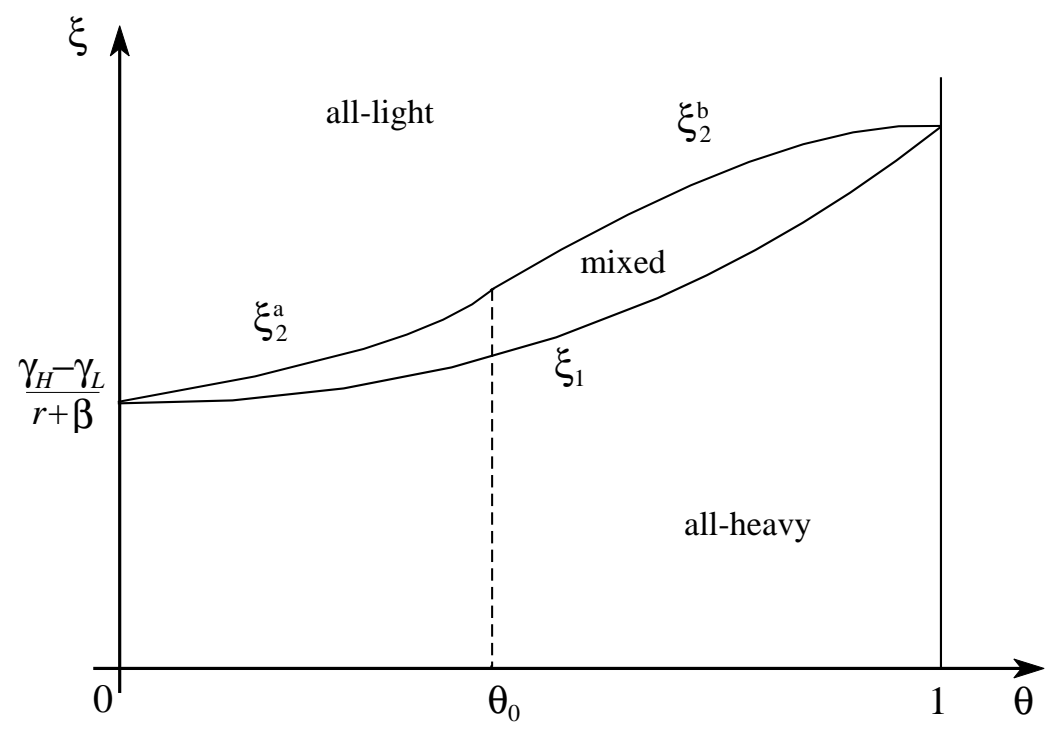

Figure 2: Equilibria after debasement, depending on the side payment and $\theta$.

We now show that in this region there is a unique equilibrium where $M_{L}$ adjusts so that agents are indifferent between going and not going to the mint: $q_{H}=q_{L}-\xi$. Such an equilibrium must be a by-tale equilibrium, because in a by-weight equilibrium $q_{H}$ and $q_{L}$ do not depend on $M_{L}$, so this indifference is generically not possible. Given this, the equilibrium conditions for this case are

$$
\begin{aligned}
r q_{H} & =\beta \theta\left[u\left(q_{H}\right)-q_{H}\right]+\beta(1-\theta)\left[u(\bar{q})-q_{H}\right]+\gamma_{H} \\
r q_{L} & =\beta \theta\left[u\left(q_{L}\right)-q_{L}\right]+\beta(1-\theta)\left[u(\bar{q})-q_{L}\right]+\gamma_{L} .
\end{aligned}
$$

These conditions can be combined to yield one equation in $q_{L}$, namely,

$$
(r+\beta) \xi=\beta \theta\left[u\left(q_{L}+\xi\right)-u\left(q_{L}\right)\right]+\gamma_{H}-\gamma_{L} .
$$

Equation (15) can be solved uniquely for $q_{L}$. Once we know $q_{L}$ and $q_{H}=q_{L}+\xi$, we simply have to find a value of $M_{L}$ in $(0,1)$ such that the implied value of $\bar{q}$ satisfies (14a). 
A little analysis indicates that one can do so if and only if $\xi$ is between $\xi_{1}$ and $\xi_{2}$, and the value of $M_{L}$ is unique. As $\xi$ increases in this range, $M_{L}$ increases from 0 to some upper bound. This upper bound is $M$ when $\theta$ is less than some $\theta_{0} \in[0,1]$, and less than $M$ when $\theta$ exceeds $\theta_{0}$ (see the proof of Lemma 5).

We emphasize that in an equilibrium with $0<M_{L}<M$ buyers always trade heavy coins to uninformed sellers; that is, it is a pure strategy by-tale equilibrium. For generic values of $\xi$, this is the only type of equilibrium with $0<M_{L}<M$ that is possible; but for certain values of $\theta$, if $\xi=\xi_{2}(\theta)$, then there also exists a by-weight equilibrium and a mixed strategy by-tale equilibrium with $M_{L} \in(0, M)$ (see the proof of Lemma 5 for details). ${ }^{24}$

We now consider the net revenue generated by a debasement, which is given by the capitalized value of the difference in the two coins' metallic content minus the one-time side payment, times the number of individuals who go to the mint:

$$
R=\left(\frac{\gamma_{H}-\gamma_{L}}{r}-\xi\right) M_{L} .
$$

Recall from Lemma 5 that $\xi_{1}(0)=\left(\gamma_{H}-\gamma_{L}\right) /(r+\beta)$. Hence, for sufficiently low values of $\theta$, we can guarantee that there is a $\xi$ that is large enough to elicit at least some reminting and yet small enough to earn net revenue $R>0$. One can also show that for sufficiently small $r$ we can choose $\xi$ so that complete reminting occurs and $R>0$ regardless of the value of $\theta$.

Suppose we want to maximize revenue. Obviously, $R$ is 0 at $\xi \leq \xi_{1}$ (since no one goes to the mint) and decreasing in $\xi$ when $\xi>\xi_{2}$ (since everyone is already going to the mint). Hence, $R$ is maximized when $\xi_{1}<\xi \leq \xi_{2}$. Although we have not been able to characterize the results analytically, numerical examples indicate that both $\xi<\xi_{2}$ and $\xi=\xi_{2}$ may maximize $R$ for different parameter values. When $R$ is maximized at $\xi<\xi_{2}$, there is partial reminting after a seigniorage-maximizing debasement: some agents voluntarily bring in their coins, others do not. In this case heavy and light coins both

${ }^{24}$ It may seem surprising that coins generically trade by tale in any equilibrium where some agents go to the mint and others do not, given that in the previous section we found by-tale or by-weight or both equilibria exist depending on parameters. The key here is that the nature of the equilibrium also depends on $M_{L}$, which is now endogenous. At the equilibrium value of $M_{L} \in(0, M)$, after a debasement, trade is by tale. 
circulate, at the same price in trade with uninformed sellers and at different prices in trade with informed sellers. ${ }^{25}$ These features of the model seem consistent with the historical experience of debasements, and are features not shared by other models that we know of.

We summarize the main results of this section in the following proposition. Most of the results are obvious from the preceding discussion; some of the more technical points follow from the proof of Lemma 5 in the Appendix.

Proposition 2. There exist critical values of the side payment, $\xi_{1}$ and $\xi_{2}$, shown in Figure 2 as functions of $\theta$, with the following properties:

(1) $\xi \leq \xi_{1}$ implies $M_{L}=0$ (no reminting);

(2) $\xi>\xi_{2}$ implies $M_{L}=M$ (complete reminting);

(3) $\xi_{1}<\xi<\xi_{2}$ implies a determinate value of $M_{L} \in(0, M)$ (partial reminting) and circulation by tale;

(4) $\xi=\xi_{2}$ (which, although nongeneric for exogenous parameter values, may occur endogenously with revenue maximization) implies one of two cases: if $(r, \theta)$ is in the by-weight region of Figure 1, then $M_{L}$ is indeterminate and we have circulation by weight, and if it is not in that region, then $M_{L}=1$;

5) small $r$ or $\theta$ implies that debasements can yield $R>0$, and depending on parameters, maximizing $R$ can yield either $\xi=\xi_{2}$ or $\xi_{1}<\xi<\xi_{2}$.

25 If revenues are maximized for $\xi=\xi_{2}$, then the outcome depends on the parameters. More precisely, when $(r, \theta)$ is in the by-weight region in Figure 1, a side payment of $\xi_{2}$ results in a by-weight equilibrium with an indeterminate mixture of heavy and light coins (although by-weight equilibria with partial reminting are nongeneric, they do exist when $\left.\xi=\xi_{2}\right)$. And when $(r, \theta)$ is not in the by-weight region in Figure 1, the outcome is a complete reminting. See the proof of Lemma 5 for details. 


\section{Conclusion}

We have constructed a random-matching or search-based model of commodity money and used it to study the circulation of various types of coins, without prior assumptions on which monies are used in which circumstances (as in cash-in-advance models) or on their rates of exchange (as in models that impose circulation by tale). The framework allows us to analyze the meaning and applicability of Gresham's Law, which we identify as a feature of a particular type of equilibrium whereby individuals abstain from trading good money - heavy coins in our model - in at least some opportunities. It those equilibria, bad money drives out good, in the sense that if there were no light coins in the economy then heavy coins would be used in all opportunities. Given private information, the presence of light coins contaminates the money supply and thereby reduces the amount a seller is willing to produce for coins whose weight he cannot recognize. The reduction in quantity, or, equivalently, the increase in price, is what limits the circulation of heavy coins.

Gresham's Law holds in what we called the by-weight equilibrium, where heavy coins always buy more than light coins (although not in strict proportion to their weight). It also holds to a lesser extent in the mixed strategy by-tale equilibrium, but not in the pure strategy by-tale equilibrium. In this latter case, all coins are traded in every meeting despite the fact that the heavy and light coins circulate by tale. By-tale circulation is more likely to obtain when information or search frictions are severe. For some values of the parameters the different types of equilibrium coexist, in which case they can be ranked in terms of welfare. This says that the extent to which Gresham's Law holds can depend on beliefs as well as fundamentals, and that it matters: the economy is worse off when bad money drives out good.

We also use the framework to analyze debasements. The goal was to capture the following historical observations from Rolnick, Velde, and Weber (1996): (1) After a debasement some individuals voluntarily went to the mint to trade heavy coins for light coins. (2) They left with less total metal than they brought in, the difference being retained as

seigniorage. (3) Debasements generated significant revenue. (4) Not all heavy coins were brought in, so that old and new coins circulated concurrently after a debasement. (5) Coins seemed to circulate by weight at least some of the time and by tale at other times. 
Our model can generate exactly these phenomena for some parameter values. In particular, the number of agents that go to the mint is determined endogenously, and when both heavy and light coins circulate after a debasement, they typically trade at the same price in some meetings and at different prices in others. These predictions are not shared by other models that we know of.

One key ingredient in the model is our private information assumption, that with some probability a seller is not able to distinguish between the coins. Given what we know about history, how reasonable is this? Although there were typically markings on the new coins that in principle distinguished them from the old coins after a debasement, these may have been difficult to detect or interpret, especially when debasements were frequent, because there could then be coins of many different vintages in simultaneous circulation. (As an aside, recall that the model predicts it is easier to debase when $\theta$ is smaller, which suggests a possible motive for the mints not wanting to make the new and old coins too recognizably different.) In any case, even without private information (that is, even with $\theta=1$ ), it is possible to generate revenue from a debasement for some values of the other parameters (for example, small $r$ ). However, without some private information we would not observe either the phenomenon of circulation by tale or Gresham's Law, since these both revolve around what happens when one meets an uniformed seller. 


\section{Appendix}

Proof of Lemma 1: We first prove that $q_{L} \leq q_{H}$. Suppose $q_{L}>q_{H}$. The proof consists of examining the various possible values for the vector $\lambda$ and deriving a contradiction.

Consider first the case $\lambda_{L K}=\Phi \in(0,1)$. This means that $u\left(q_{L}\right)=q_{L}$, that is, $q_{L}=\hat{q}$. By assumption, $q_{H}<\bar{q}<\hat{q}$, which implies $\lambda_{H K}=1, \lambda_{H U}=1$. Moreover, $u(\bar{q}) \leq$ $u\left(q_{L}\right)=q_{L}$ or $\lambda_{L U}\left[u(\bar{q})-q_{L}\right]=0$ and therefore $q_{L}=\gamma_{L} / r$. Since $q_{H} \geq \gamma_{H} / r>\gamma_{L} / r$ we have a contradiction.

Consider now $\lambda_{H K}=\Phi$ : by similar reasoning it can be shown that $q_{L}=\gamma_{L} / r$, yielding the same contradiction. Consider the case $\lambda_{H K}=0: u\left(q_{H}\right)<q_{H}$ implies $q_{H}>\hat{q}$; by assumption $q_{L} \geq \bar{q}>q_{H}$ so $\lambda_{L K}=0$ and $\lambda_{L U}=0$. This implies $q_{L}=\gamma_{L} / r<\gamma_{H} / r \leq$ $q_{H}$, a contradiction.

Having ruled out $\lambda_{H K}=0$ or $\Phi$, only $\lambda_{H K}=1$ remains. It implies that $u\left(q_{H}\right)>q_{H}$, and by assumption $\bar{q}>q_{H}$ so $u(\bar{q})>u\left(q_{H}\right)>q_{H}$ or $\lambda_{H U}=1$. Suppose $\lambda_{L K}=0$ : $u\left(q_{L}\right)<q_{L}$ implies $u(\bar{q})<q_{L}$ or $\lambda_{L U}=0$ and $q_{L}=\gamma_{L} / r$ which, as before, contradicts $q_{L}<q_{H}$. Since we have already ruled out $\lambda_{L K}=\Phi$, only $\lambda_{L K}=1$ remains. Since $\lambda_{H U}=1$, then either $\lambda_{L U}=0$ or $\lambda_{L U}>0$.

In the first case, $q_{H}=\bar{q}$ and the Bellman equations reduce to

$$
\begin{aligned}
r q_{H} & =\beta\left[u\left(q_{H}\right)-q_{H}\right]+\gamma_{H} \\
r q_{L} & =\beta \theta\left[u\left(q_{L}\right)-q_{L}\right]+\gamma_{L} .
\end{aligned}
$$

Clearly, $q_{L}<\beta\left[u\left(q_{L}\right)-q_{L}\right] / r+\gamma_{H} / r$. Consider the function $f(q)=\beta[u(q)-q] / r+\gamma_{H} / r-q$ : this function satisfies $f(0)>0, f(\hat{q})<0, f\left(q_{H}\right)=0$ and $f^{\prime}(q)$ changes sign at most once because $u^{\prime}$ is decreasing: therefore $f$ changes sign only once, and $f(q)>0$ implies $q<q_{H}$. This shows that $q_{L}<q_{H}$ which is a contradiction.

The only case that remains is then $\lambda_{H K}=\lambda_{L K}=\lambda_{H U}=1, \lambda_{L U}>0$. In this case, the Bellman equations become:

$$
q_{i}=\frac{\beta \theta}{r+\beta} u\left(q_{i}\right)+\frac{\gamma_{i}}{r+\beta}+\frac{\beta(1-\theta)}{r+\beta} u(\bar{q})
$$


Define

$$
g(q)=\frac{\beta \theta}{r+\beta} u(q)+\frac{\gamma_{H}}{r+\beta}+\frac{\beta(1-\theta)}{r+\beta} u(\bar{q})-q .
$$

Note that $g(0)>0, g(\hat{q})<0$, and $g^{\prime}$ changes sign at most once, so that $g$ starts as positive and changes sign only once. Since $g\left(q_{H}\right)=0$ and $g\left(q_{L}\right)=\left(\gamma_{H}-\gamma_{L} /(r+\beta)>0\right.$, it must be that $q_{L}<q_{H}$, a contradiction.

This establishes that that $q_{L} \leq q_{H}$. To conclude the proof, simply notice that when $q_{L}=q_{H}=\bar{q}$ Bellman's equations are satisfied if and only if $\gamma_{H}=\gamma_{L}$.

Proof of Lemma 2: $\quad$ Suppose $\lambda_{H K}=\Phi$, which means $u\left(q_{H}\right)=q_{H}$. By Lemma 1, $u(\bar{q}) \leq u\left(q_{H}\right)=q_{H}$, which means that $\lambda_{H U}\left[u(\bar{q})-q_{H}\right]=0$. Using (5), we find that $r q_{H}=\gamma_{H}$. This can be an equilibrium only if $u\left(\gamma_{H} / r\right)=\gamma_{H} / r$, which is not generic.

Suppose $\lambda_{L K}=\Phi$, which means $u\left(q_{L}\right)=q_{L}=\hat{q}$. Then, by Lemma $1, q_{H}>q_{L}=\hat{q}$ so that $u\left(q_{H}\right)<q_{H}$ and therefore $\lambda_{H K}=0$. Also, by Lemma $1, \bar{q} \leq q_{H}$ so that $u(\bar{q}) \leq$ $u\left(q_{H}\right)<q_{H}$ and therefore $\lambda_{H U}=0$; this means $\pi=0$ and $\bar{q}=q_{L}$. In (5), this allows to solve for $q_{L}=\gamma_{L} / r$ which must satisfy $u\left(\gamma_{L} / r\right)=\gamma_{L} / r$, which is not generic.

Finally, suppose $\lambda_{L U}=\Phi$, which means $u(\bar{q})=q_{L}$. By Lemma $1, q_{L}<q_{H}$ so that $u(\bar{q})=q_{L}<q_{H}$ and $\lambda_{H U}=0$. Again, this implies $\pi=0$ and $\bar{q}=q_{L}$. Therefore $u\left(q_{L}\right)=q_{L}$ and $\lambda_{L K}\left[u\left(q_{L}\right)-q_{L}\right]=0$, so that $q_{L}=\gamma_{L} / r$ and the condition $u\left(\gamma_{L} / r\right)=\gamma_{L} / r$ must hold, which is also not generic.

Proof of Lemma 3: The by-weight frontier $\theta=f_{w}(r)$ is defined by:

$$
\begin{aligned}
r q_{L} & =\beta\left[u\left(q_{L}\right)-q_{L}\right]+\gamma_{L} \\
r q_{H} & =\beta \theta\left[u\left(q_{H}\right)-q_{H}\right]+\gamma_{H} \\
q_{H} & =u\left(q_{L}\right)
\end{aligned}
$$

The by-tale frontier $\theta=f_{t}(r)$ is defined by:

$$
\begin{aligned}
r q_{L} & =\beta \theta\left[u\left(q_{L}\right)-q_{L}\right]+\beta(1-\theta)\left(q_{H}-q_{L}\right)+\gamma_{L} \\
r q_{H} & =\beta \theta\left[u\left(q_{H}\right)-q_{H}\right]+\gamma_{H} \\
q_{H} & =u\left[\pi q_{H}+(1-\pi) q_{L}\right]
\end{aligned}
$$


with $\pi=M_{H} / M$.

Consider the by-weight frontier first, and fix $\theta$. In the $\left(q_{H}, q_{L}\right)$ plane, (17a) and (17b) define a curve parameterized by $r$ (call it curve $A$ ). We look for an intersection of curve $A$ with the curve defined by (17c) (call it curve $B$ ) as $r$ varies from $\gamma_{H} / \hat{q}$ to $+\infty$.

First, we establish the properties of curve $A$. For $r=\gamma_{H} / \hat{q}, q_{H}(r)=\hat{q}$ and $q_{L}(r)<$ $q_{H}(r)=\hat{q}$. As $r \rightarrow+\infty, \lim \left(q_{H}\right)=\lim \left(q_{L}\right)=0$ and $\lim \left(q_{H} / q_{L}\right)=\gamma_{H} / \gamma_{L}<+\infty$. Moreover,

$$
\frac{d q_{H}}{d q_{L}}=\frac{q_{H}}{q_{L}} \frac{r-\beta\left[u^{\prime}\left(q_{L}\right)-1\right]}{r-\beta \theta\left[u^{\prime}\left(q_{H}\right)-1\right]}
$$

and $0<d q_{H} / d q_{L}<q_{H} / q_{L}$, because (17a) and (17b) together with concavity of $u$ imply $r>\beta\left[u^{\prime}\left(q_{L}\right)-1\right]$ and $r>\beta \theta\left[u^{\prime}\left(q_{H}\right)-1\right]$ (see proof of Lemma 4), and $q_{L}<q_{H}$ implies $u^{\prime}\left(q_{H}\right)<u^{\prime}\left(q_{L}\right)$ which leads to $r-\beta\left[u^{\prime}\left(q_{L}\right)-1\right]<r-\beta \theta\left[u^{\prime}\left(q_{H}\right)-1\right]$. Therefore, curve $A$ is increasing and concave.

On the other hand, curve $B$ (which is the graph of $u$ ) starts at the point $(0,0)$ with $\lim \left(q_{H} / q_{L}\right)=u^{\prime}(0)=+\infty$, is increasing and concave, and includes the point $(\hat{q}, \hat{q})$. Since curve $A$ starts at $(0,0)$ with finite slope, it is initially below curve $B$, but it is above curve $B$ when it intersects the horizontal line $q_{H}=\gamma / \hat{q}$. Therefore, there is at least one intersection of the two curves, that is, at least one value of $r$ for any $\theta \in[0,1]$ for which the by-weight frontier is well-defined.

The same reasoning can be applied to the by-tale frontier: equations (18a) and (18b) define another curve (call it $\left.A^{\prime}\right)$ in the same $\left(q_{H}, q_{L}\right)$ plane with the same properties, and for each $\theta \in[0,1]$ there is at least one $r$ for which this curve intersects the curve defined by (18c) (call it curve $B^{\prime}$ ).

For $\theta=1$, curves $A$ and $A^{\prime}$ coincide. This leads to Figure 3 , which shows that the lowest value $r_{t}$ such that $\left(r_{t}, 1\right)$ is on the by-tale frontier is smaller the the lowest value $r_{w}$ such that $\left(r_{w}, 1\right)$ is on the by-weight frontier. Inspection of equations (17) and (18) shows that the two frontiers cannot intersect on their interior (unless $\bar{q}=q_{L}$, which occurs when $\left.M_{H}=0\right)$. Therefore, the by-weight frontier always lies below the by-tale frontier in the $(r, \theta)$ plane. 


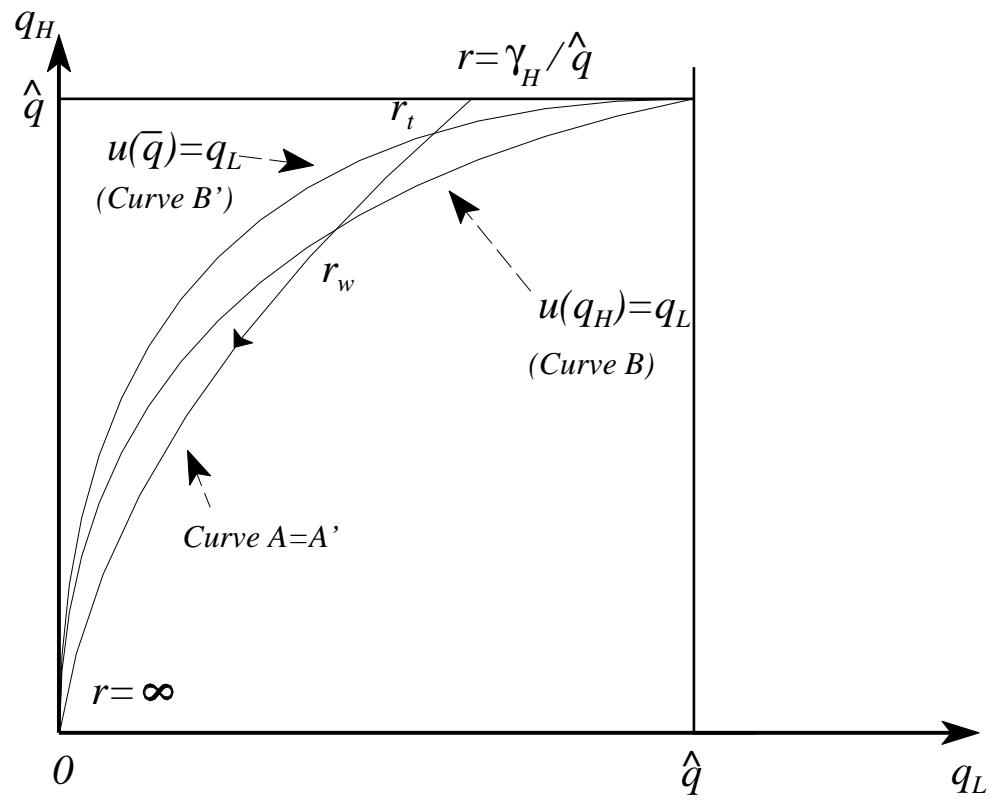

Figure 3: Existence of by-weight and by-tale frontiers.

Proof of Lemma 4: We will use a pair of functions to establish an ordering on the equilibrium values in the pure-strategy by-tale $(P B T)$, mixed-strategy by-tale $(M B T)$ and by-weight $(B W)$ equilibria.

For $i=H, L$, define the function

$$
F_{i}(q, x)=\beta \theta[u(q)-q]+\beta(1-\theta)(x-q)+\gamma_{i}-r q
$$

on $[0, \hat{q}]^{2}$. For any $x, F_{i}(0, x)=\beta(1-\theta) x+\gamma_{i}>0$ and $F_{i}(\hat{q}, x)=\beta(1-\theta)(x-\hat{q})+\gamma_{i}-r \hat{q}<$ 0 ; therefore, there exists $q$ such that $F_{i}(q, x)=0$. Moreover,

$$
\begin{aligned}
\frac{\partial F_{i}}{\partial q}(q, x) & =\beta \theta u^{\prime}(q)-(r+\beta) \\
& <\beta \theta u(q) / q-(r+\beta)=\frac{F_{i}(q, x)-F_{i}(0, x)}{q}
\end{aligned}
$$


so that $F_{i}(\cdot, x)$ is concave (notice that $\partial F_{i} / \partial q$ does not depend on $x$ ). Therefore the solution to $F_{i}(q, x)=0$ is unique (given $x$ ). By the implicit function theorem, there is a function $q_{i}(x)$ such that $F_{i}[q(x), x]=0$, and it can be shown that $q^{\prime}(x)>0$.

We use the following notation for the equilibrium values: $q_{H}^{*}, \bar{q}^{*}$ and $q_{L}^{*}$ in the $P B T$ equilibrium, defined by $(9) ; q_{H}^{+}, \bar{q}^{+}$and $q_{L}^{+}$in the $M B T$ equilibrium, defined by (10); and $q_{H}$ and $q_{L}$ in the $B W$ equilibrium, defined by (8).

Consider first $q_{H}^{*}$ and $q_{H}$. For some $\tilde{q}$ between $q_{H}^{*}$ and $q_{H}$, we have

$$
\begin{aligned}
\frac{F_{H}\left(q_{H}, q_{H}^{*}\right)-F_{H}\left(q_{H}^{*}, q_{H}^{*}\right)}{q_{H}-q_{H}^{*}} & =\frac{\partial F_{H}}{\partial q}\left(\tilde{q}, q_{H}^{*}\right) \\
\frac{u\left(\bar{q}^{*}\right)-q_{H}^{*}}{q_{H}-q_{H}^{*}} \beta(1-\theta) & =\frac{\partial F_{H}}{\partial q}\left(\tilde{q}, q_{H}^{*}\right)+\beta(1-\theta)
\end{aligned}
$$

Suppose $q_{H}>q_{H}^{*}$ : then the left-hand side of (19) is positive (since the incentive constraint in a $P B T$ equilibrium is $\left.u\left(\bar{q}^{*}\right)>u\left(q_{H}^{*}\right)\right)$. On the other hand, $q_{H}^{*}<\tilde{q}<q_{H}$ and

$$
\begin{aligned}
\partial F_{H} / \partial q\left(\tilde{q}, q_{H}^{*}\right) & <\partial F_{H} / \partial q\left(q_{H}^{*}, q_{H}^{*}\right) \\
& <\partial F_{H} / \partial q\left[q_{H}^{*}, u\left(\bar{q}^{*}\right)\right]<-F_{H}\left[0, u\left(\bar{q}^{*}\right)\right] / q_{H}^{*} \\
& <-\beta(1-\theta) u\left(\bar{q}^{*}\right) / q_{H}^{*}-\gamma_{H}<-\beta(1-\theta),
\end{aligned}
$$

recalling that $\partial F / \partial q$ does not depend on its second argument, and that, by (9), we have $F_{H}\left[q_{H}^{*}, u\left(\bar{q}^{*}\right)\right]=0$. It follows that the right-hand side of (19) is negative, a contradiction. Therefore $q_{H}^{*} \geq q_{H}$.

We now rank $q_{L}^{*}$ and $q_{L}$. First, we see that $u\left(\bar{q}^{*}\right)>u\left(q_{L}\right)$; otherwise, $u\left(q_{L}\right)>$ $u\left(\bar{q}^{*}\right)>q_{H}^{*} \geq q_{H}$ which violates the incentive constraint for a $B W$ equilibrium. Next, by (9), $F_{L}\left[q_{L}^{*}, u\left(\bar{q}^{*}\right)\right]=0$ and by $(8), F_{L}\left[q_{L}, u\left(q_{L}\right)\right]=0$; therefore, from the properties of $F_{L}$, $q_{L}<q_{L}^{*}$ : a $P B T$ equilibrium Pareto-dominates a $B W$ equilibrium.

Now, consider the $M B T$ equilibrium: by $(10), F_{L}\left(q_{L}^{+}, q_{H}\right)=0$ and $F_{L}\left[q_{L}, u\left(q_{L}\right)\right]=$ 0 ; the incentive constraint in a $B W$ equilibrium being $q_{H}>u\left(q_{L}\right)$, by the properties of $F_{L}$ we have that $q_{L}<q_{L}^{+}$. Notice that $q_{H}=q_{H}^{+}$, since (8a) and (10a) are identical. Therefore a $M B T$ equilibrium dominates a $B W$ equilibrium. 
To conclude, $F_{L}\left[q_{L}^{*}, u\left(\bar{q}^{*}\right)\right]=0$ and $F_{L}\left(q_{L}^{+}, q_{H}\right)=0$; and $u\left(\bar{q}^{*}\right)>q_{H}^{*}>q_{H}$ implies $q_{L}^{*}>q_{L}^{+}$. Since $q_{H}^{*}>q_{H}=q_{H}^{+}$, a $P B T$ equilibrium dominates a $M B T$ equilibrium.

Proof of Lemma 5: Consider the first the maximal side payment for which an equilibrium results where no one goes to the mint, $\xi_{1}=q_{H}-q_{L}$, where $q_{H}$ and $q_{L}$ solve (12). Then $\xi_{1}$, as a function of $\theta$, satisfies:

$$
\xi_{1}(\theta)=\frac{\beta}{r+\beta} \theta\left[u\left(q_{H}\right)-u\left(q_{L}\right)\right]+\frac{\gamma_{H}-\gamma_{L}}{r+\beta} .
$$

Notice that

$$
\begin{aligned}
& \xi_{1}(0)=\frac{\gamma_{H}-\gamma_{L}}{r+\beta}, \\
& \xi_{1}(1)=\frac{\beta}{r+\beta}\left[u\left(q_{H}^{*}\right)-u\left(q_{L}^{*}\right)\right]+\xi_{1}(0),
\end{aligned}
$$

with $\left(q_{H}^{*}, q_{L}^{*}\right)$ defined by

$$
\begin{gathered}
r q_{H}^{*}=\beta\left[u\left(q_{H}^{*}\right)-q_{H}^{*}\right]+\gamma_{H}, \\
r q_{L}^{*}=\beta\left[u\left(q_{L}^{*}\right)-q_{L}^{*}\right]+\gamma_{L} .
\end{gathered}
$$

As $\theta$ varies, $q_{H}=q_{H}^{*}$ is a constant. It can be shown that the value of $q_{L}$ for $\theta=0$ is greater than $q_{L}^{*}$ which is the value of $q_{L}$ for $\theta=1$, that

$$
\frac{\partial q_{L}}{\partial \theta}=\frac{N\left[u\left(q_{H}\right)-u\left(q_{L}\right)\right]}{\beta \theta u^{\prime}\left(q_{L}\right)-(r+\beta)}
$$

and that $\beta \theta u^{\prime}\left(q_{L}\right)-(r+\beta)<0$ for $q_{L}>q_{L}^{*}$, using (22) and the concavity property that $u^{\prime}(q) q<u(q)$. Therefore, for all $\theta, q_{L}$ is decreasing in $\theta$, and $\xi_{1}(\theta)$ is increasing in $\theta$ since $\partial \xi_{1} / \partial \theta=-\partial q_{L} / \partial \theta$. The values of $q_{H}$ and $q_{L}$, which are the values for a by-tale equilibrium with $M_{L}=0$, are shown in Figure 4 (they are marked $B T 0$ ).

We now study the minimal side payment size for which an equilibrium results where everyone goes to the mint. Let $\xi_{2}=q_{H}-q_{L}$ where $q_{H}$ and $q_{L}$ solve (13). When $\lambda_{H U}=1$, from (13) we have

$$
\begin{aligned}
r q_{L} & =\beta\left[u\left(q_{L}\right)-q_{L}\right]+\gamma_{L} \\
r q_{H} & =\beta \theta\left[u\left(q_{H}\right)-q_{H}\right]+\beta(1-\theta)\left[u\left(q_{L}\right)-q_{H}\right]+\gamma_{H},
\end{aligned}
$$




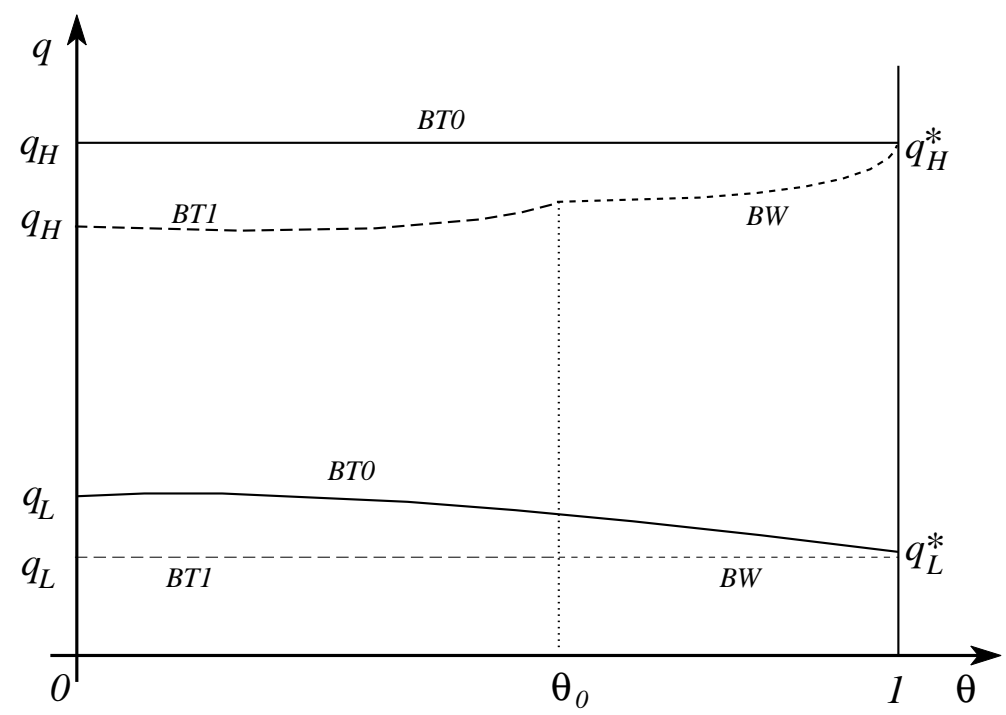

Figure 4: Value of Heavy and Light Coins after Debasement ( $r$ given).

as long as these values satisfy $u\left(q_{L}\right)>q_{H}$. Note that $q_{L}=q_{L}^{*}$ does not vary with $\theta$, while $q_{H}$ does; these values correspond to a by-tale equilibrium with $M_{L}=M$, and are plotted in Figure 4 as BT1.

When $q_{H}$ reaches $u\left(q_{L}^{*}\right), \lambda_{H U}$ becomes 0 , from (13) we have:

$$
\begin{aligned}
r q_{L} & =\beta\left[u\left(q_{L}\right)-q_{L}\right]+\gamma_{L} \\
r q_{H} & =\beta \theta\left[u\left(q_{H}\right)-q_{H}\right]+\gamma_{H} .
\end{aligned}
$$

These values correspond to a by-weight equilibrium and are plotted in Figure 4 as marked $B W$. As $\theta$ increases, $\lambda_{H U}=0$ while $\theta$ lies inside the by-weight region, and $\lambda_{H U}$ switches to 1 at the by-weight frontier. From Figure 1, we know that values of $\theta$ inside the byweight region lie in an interval $\left[\theta_{0}, 1\right]$ where $\theta_{0}=f_{w}^{-1}(r)$ in the notation of Lemma 3 and $0 \leq \theta_{0} \leq 1$. Thus, $\xi_{2}$ is defined in at most two pieces, $\xi_{2}^{a}(\theta)$ for $\left[0, \theta_{0}\right]$ with $\lambda_{H U}=1$, and $\xi_{2}^{b}(\theta)$ for $\left[\theta_{0}, 1\right]$ with $\lambda_{H U}=0$. 
Consider first the case where $\lambda_{H U}=1$. The expression for $\xi_{2}^{a}$, in terms of the equilibrium values, is:

$$
\xi_{2}^{a}(\theta)=q_{H}-q_{L}=\frac{\beta}{r+\beta} \theta\left[u\left(q_{H}\right)-u\left(q_{L}\right)\right]+\frac{\gamma_{H}-\gamma_{L}}{r+\beta},
$$

which is algebraically identical to (20), but with different equilibrium values for $q_{H}$ and $q_{L}$. However,

$$
\begin{aligned}
& \xi_{2}^{a}(0)=\frac{\gamma_{H}-\gamma_{L}}{r+\beta}=\xi_{1}(0), \\
& \xi_{2}(1)=\frac{\beta}{r+\beta}\left[u\left(q_{H}^{*}\right)-u\left(q_{L}^{*}\right)\right]+\xi_{1}(0)=\xi_{1}(1) .
\end{aligned}
$$

A comparison of (20) and (23), and the concavity of $u$, imply that $\xi_{1}(\theta)=\xi_{2}^{a}(\theta)$ only for $\theta=0$ or identical values of $q_{H}$ and $q_{L}$, which can only happen at $\theta=1$ where $q_{L}=q_{L}^{*}$ and $q_{H}=q_{H}^{*}$ in both cases. Moreover,

$$
\frac{\partial \xi_{2}^{a}}{\partial \theta}=\frac{\partial q_{H}}{\partial \theta}=\frac{\beta\left[u\left(q_{H}\right)-u\left(q_{L}\right)\right]}{r+\beta-\theta u^{\prime}\left(q_{H}\right)}>0,
$$

so that, at $\theta=0$, the expressions for $\partial \xi_{i} / \partial \theta$ are algebraically identical, namely

$$
\frac{\partial \xi_{i}}{\partial \theta}=\frac{\beta}{r+\beta}\left[u\left(q_{H}\right)-u\left(q_{L}\right)\right] .
$$

But the pair $\left(q_{H}, q_{L}\right)$ in the all-heavy equilibrium strictly dominates the pair $\left(q_{H}, q_{L}\right)$ in the all-light equilibrium (see Figure 4), while the difference $q_{H}-q_{L}$ is equal; therefore $u\left(q_{H}\right)-u\left(q_{L}\right)$ is larger in the all-light equilibrium, and $\partial\left(\xi_{2}^{a}-\xi_{1}\right) /\left.\partial \theta\right|_{\theta=0}>0$. This shows that $\xi_{2} \geq \xi_{1}$ for all $\theta$ with equality only at $\theta=0$ and $\theta=1$.

We now consider the case where $\lambda_{H U}=0$. Then, $\xi_{2}^{b}(\theta)$ is defined by:

$$
\xi_{2}^{b}(\theta)=\frac{\beta \theta}{r+\beta \theta}\left[u\left(q_{H}\right)-u\left(q_{L}\right)\right]+\frac{\gamma_{H}}{r+\beta \theta}-\frac{\gamma_{L}}{r+\beta}+\frac{\beta(1-\theta)}{r+\beta}\left[q_{H}-u\left(q_{L}\right)\right] .
$$

Note that, for $\theta=1, q_{H}=q_{H}^{*}$ and $\xi_{2}^{b}(1)=\xi_{1}(1)$. It is easy to check that $\partial q_{H} / \partial \theta$ is still positive; so that the qualitative features of $\xi_{2}$ are unchanged, except for the fact that $\xi_{2}^{b}(0)>\xi_{1}(0)$; thus, in the cases where $\theta_{0}=0$, then $\xi_{2}$ does not coincide with $\xi_{1}$ at 0 .

For values of the side payment exactly equal to $\xi_{2}^{b}$, a by-weight equilibrium can result from debasement, with $M_{L}$ indeterminate, since the equilibrium values $q_{H}$ and $q_{L}$ 
are such that $q_{H}=\xi+q_{L}$ and satisfy the by-weight conditions; but values in a by-weight equilibrium do not depend on $M_{L}$, so that the amount of minting following a debasement is indeterminate. This occurs only when $\xi$ is exactly equal to $\xi_{2}^{b}$, which is non-generic. Note, however, that $\xi=\xi_{2}^{b}$ is consistent with another pair of equilibrium values, namely $q_{H}$ and $q_{L}$ for a by-tale equilibrium where $\lambda_{H U}=0$ and $M_{L}<M$. Thus, $\xi_{2}$ can be seen as consistent with a by-tale, $M_{L}=M$ equilibrium for $\left[0, \theta_{0}\right]$ and with a by-weight or a by-tale, $M_{L}<M$ equilibrium for $\left[\theta_{0}, 1\right]$.

\section{REFERENCES}

Aiyagari, S. Rao. "Gresham's Law in a Lemons Market for Assets." Canadian Journal of Economics, August 1989, 22(3), pp. 686-97.

Akerlof, George A. "The Market for 'Lemons': Quality Uncertainty and the Market Mechanism." Quarterly Journal of Economics, August 1970, 84(3), pp. 488-500.

Banerjee, Abhijit V. and Eric S. Maskin. "A Walrasian Theory of Money and Barter." Quarterly Journal of Economics, November 1996, 111(4), pp. 955-1005.

Camera, Gabriele and Dean Corbae. "On the Distribution of Money and Prices with Search." Mimeo, University of Iowa, 1996.

Cipolla, Carlo M. Money, Prices and Civilization in the Mediterranean World, Fifth to Seventeenth Century. New York: Gordian Press, 1956.

Cuadras-Morató, Xavier. "Commodity Money in the Presence of Goods of Heterogeneous Quality." Economic Theory, May 1994, 4(3), pp. 579-91.

Friedman, Milton and Anna J. Schwartz. A Monetary History of the United States, 18671960. Princeton: Princeton University Press, 1963.

Green, Edward J. and Warren E. Weber. "Will the New $\$ 100$ Bill Decrease Counterfeiting?" Federal Reserve Bank of Minneapolis Quarterly Review, Summer 1996, 19(3), pp. $3-10$. 
Green, Edward J. and Ruilin Zhou. "A Rudimentary Model of Search with Divisible Money and Prices." Mimeo, University of Pennsylvania and Federal Reserve Bank of Minneapolis, 1996.

Greenfield, Robert L., and Hugh Rockoff. "Gresham's Law in Nineteenth-Century America." Journal of Money, Credit and Banking, November 1995, 27(4), pp. 1086-98.

Kim, Young Sik. "Money, Barter and Costly Information Acquisition." Journal of Monetary Economics, February 1996, 37(1), pp. 119-42.

Kiyotaki, Nobuhiro and Randall Wright. "On Money as a Medium of Exchange." Journal of Political Economy, August 1989, 97(4), pp. 927-54.

Kiyotaki, Nobuhiro, and Randall Wright. "A Contribution to the Pure Theory of Money." Journal of Economic Theory, April 1991, 53(2), pp. 215-35.

Kiyotaki, Nobuhiro, and Randall Wright. "A Search-Theoretic Approach to Monetary Economics." American Economic Review, March 1993, 83(1), pp. 63-77.

Laughlin, J. Laurence. The Principles of Money. New York: G. Scribner's Sons, 1903.

Li, Yiting. "Commodity Money under Private Information." Journal of Monetary Economics, December 1995, 36(3), pp. 573-92.

Miskimin, Harry. "Money, the Law and Legal Tender," in Georges Depeyrot, Tony Hackens, Ghislaine Moucharte, eds., Rythmes de la production monétaire de l'antiquité à nos jours. Louvain-la-Neuve: Collège Érasme, 1987.

Molico, Miguel. "The Distribution of Money and Prices in Search Equilibrium." Mimeo, University of Pennsylvania, 1996.

Ostroy, Joseph M., and Ross M. Starr. "The Transaction Role of Money," in Benjamin M. Friedman and Frank K. Hahn, eds., Handbook of Monetary Economics. Amsterdam: North-Holland, 1990.

Rolnick, Arthur J., and Warren E. Weber. "Gresham's Law or Gresham's Fallacy?" Journal of Political Economy, February 1986, 94(1), pp. 185-99. 
Rolnick, Arthur J., François R. Velde, and Warren E. Weber. "The Debasement Puzzle: An Essay in Medieval Monetary Economics." Journal of Economic History, December 1996, 56(4), pp. 789-808.

De Roover, Raymond. Gresham on Foreign Exchange. Cambridge, MA: Harvard University Press, 1949.

Sargent, Thomas J., and Bruce D. Smith. "Coinage, Debasements, and Gresham's Laws." Economic Theory, 1997, forthcoming.

Sargent, Thomas J., and Neil Wallace. "A Model of Commodity Money." Journal of Monetary Economics, July 1983, 12(1), pp. 163-87.

Shi, Shouyong. "Money and Prices: A Model of Search and Bargaining." Journal of Economic Theory, December 1995, 67(2), pp. 467-498.

Trejos, Alberto, and Randall Wright. "Search, Bargaining, Money, and Prices." Journal of Political Economy, February 1995, 103(1), pp. 118-141.

Trejos, Alberto. "Money, Prices and Private Information." Mimeo, Northwestern University, 1994.

Trejos, Alberto. "Incentives to Produce Quality and the Liquidity of Money." Economic Theory, 1997, forthcoming.

Williamson, Stephen D. "Laissez-Faire Banking and Circulating Media of Exchange." Journal of Financial Intermediation, June 1992, 2(2), pp. 134-67.

Williamson, Stephen D., and Randall Wright. "Barter and Monetary Exchange Under Private Information." American Economic Review, March 1994, 84(1), pp. 104-23.

Zhou, Ruilin. "Inventory Holdings of Money and Indeterminacy of Search Equilibrium" Mimeo, University of Pennsylvania and Federal Reserve Bank of Minneapolis, 1996. 